\title{
Standardization of Design Interfaces Applied to Language Test on-line through Ubiquitous Devices
}

\author{
https://doi.org/10.3991/ijim.v12i4.9197 \\ Teresa Magal-Royo $\left.{ }^{\square}\right)$ \\ Universitat Politécnica de Valencia, Valencia, Spain \\ tmagal@degi.upv.es \\ Jesús García Laborda \\ Universidad de Alcalá, Madrid, Spain
}

\begin{abstract}
Normalization of design rules and guidelines in English language tests to help future instructors and assessment developers in the field of examination of English as a foreign language. have not been defined sufficiently until present days

In fact, there are several experiences and investigations related to the user's experiences in the handling of computer exams for learning a foreign language that have been evaluated in, for and through different experimental interactive digital environments.

These interactive scenarios oriented to the user experience, UX in the ubiquitous devices, have allowed to learn technological, functional and design aspects that will be necessary in the future to establish the standards in design and vision for language tests in its online environment.

The lack of effective and realistic regulations has become a functional requirement for the progress of research on digital environments adapted to the needs of competence assessment and more specifically, to the learning environment of foreign language (FL).

Proliferation of on-line tests of language certification of ls with a structural corpus depends on where there are not really functional and formal guidelines that allow evaluating their quality and adequacy from the experience of the user and according to the level of learning competences acquired in a foreign language.

This article describes aspects of design that should be taken into account when defining an online test of languages in a ubiquitous device that will mark verifiable guidelines of a general nature and affect the evaluation task in the formation of languages that need to be checked and evaluated periodically.
\end{abstract}

Keywords-m-learning, English as a Foreign Language, Mobile-Assisted Language Learning (MALL), User Experience (UX), normalization, online test, design 


\section{Introduction}

Language exams for learning have evolved in the last 20 years due to the spectacular increase in the need for language certifications worldwide that currently directly affect the educational and social systems of each country. The mobility of people at a global level implies the need to have a communication channel - a language that allows them to develop socially in countries other than their own. The acquisition of a foreign language is turning into a vital aspect for social and communicative integration that in many cases is being regulated to verify its effectivity. Therefore, there is currently a proliferation of certified exams that verify the levels of knowledge or skills of the person from a regulated point of view.at educational and professional level

The current situation in the field of investigations focused on the evaluation applied to the knowledge of a foreign language have been developed in three areas: 1, The external evaluation carried out by international evaluating entities of a public or private nature (Educational Testing Service, Cambridge Board of Examinations ${ }^{\mathrm{TM}}$, Trinity College Examinations ${ }^{\mathrm{TM}}$, etc.), 2- The computer-assisted examinations organized by educational institutions for the improvement of students' competences. 3The development of new on-line evaluation methods based on ubiquitous devices that facilitate learning methods based on m-learning and b-learning.

Most of the exams or tests have the same structure and work with the same competence parameters of and skills assessment that directly affect the learning of a language such as grammar, vocabulary, conversation, etc. In fact, learning of a foreign language and its certification maintains many traditional schemes that have been implemented in computer-assisted language learning and more specifically in MobileAssisted Language Learning (MALL). Current increase in application for the learning of ad-hoc languages based on collaborative environments, and collaboration on mobile devices that includes test-type assessment tests which allow both qualitative or quantitative evaluation of progress of each learner. Burston also points out that $75 \%$ of all MALL Apps are focused on individual learning as opposed to traditional teacher-centred, instruction [1], [2].

Tests or exams are usually implemented on the digital educational platforms as a part of the training process and verification of learning about a specific topic. The process of creation and implementation of a new tests is generated in a traditional way by selecting a specific type of questions (questions with long and / or short answer, true / false, selection of options, etc.), determination of a quantitative or qualitative qualification format and finally by a way of collecting the overall mark of all the tests carried out to obtain a total or partial assessment that serves as a complement to the student's learning [3].

The creation of a conventional on-line test establishes the development of a backend or internal platform where all the technical and formal aspects of exams creation are generated and implemented, and a front-end external platform oriented to the student that is used in a controlled and monitored way visualized in different devices [4]. 
The visualization of the front-office of the foreign language test or the certification test is done within the final stages of the development process in the digital environment by following the administration agency's guidelines which in turn are set by the navigation philosophy of the digital platform using the same data source and type of interface that was formally adapted to digital content depending on the size of a device such as tablet, PC and smartphone [5]. As it can be summarized, the process usually begins by pen-and-paper, then it goes online for large screen devices and finally, if so desired, it will be finally adapted to mobile devices. This is a debatable approach obviously but it fits perfectly in the principle of economy since the creation of specifically aimed (to mobile devices) of testing platforms can dramatically increase the complexity and thus the price.

\section{Interaction methods in management and access of information in language certification of on-line tests}

Due to the evolution of capacity and functionality of ubiquitous devices, an information access framework is needed for the design process: The use of interactions with the user that are increasingly natural and combined with more than one channel as is the case of applications based on multimodal interaction methods creates a better experience for the test candidate. In the case of multiple choice exams, multimodality will be a future line of research that will mark the evolution in the development of navigation processes on a specific exam such as the case of language testing [6].

Multimodal interaction is a process in which the device and the user are able to perform a joint interaction - whether auditory, visual, tactile or kinaesthetic, at any place and any time in an accessible way. The study of levels of multimodal integration is related to the technological use of connected interaction [7].

This method of interaction allows us to simulate human communication where, for example, verbal communication is a simultaneous set of perceptions obtained from sight, hearing, gestures, etc. It permits us to have an idea about the situation, the context in which we speak, recognize the interlocutor and respond to the message received. Multimodal interfaces can reduce the recognition of errors by the user because the user can confirm data in multimodal way and through several channels. Combining entries by different modalities can improve the recognition of a task (see Figure 1). Through multimodal interaction, users can determine a mode or different modes of interaction needed to be used during the process of accessing information by either keyboard, mouse, pencil, touch screens, voice, etc, on an interface specially developed for it [8]. In the case of test development for language certification exams on a ubiquitous device, the most common interaction option is a touch screen used by many applications for tablets in the educational field. 


\begin{tabular}{|c|c|c|c|c|}
\hline $\begin{array}{c}\text { Channel/Data } \\
\text { Entry }\end{array}$ & DEVICE & INTERFACE & USER SETTINGS & ACTIONS \\
\hline View & Screen & \multicolumn{3}{|c|}{ PERFORMANCE CONDITIONS } \\
\hline & & $\begin{array}{l}\text { Screen access } \\
\text { to a viewing } \\
\text { configuration }\end{array}$ & $\begin{array}{l}\text { Resolution screen / } \\
\text { brighness/ contrast } \\
\text { configuration }\end{array}$ & $\begin{array}{l}\text { Visual access to information } \\
\text { about test questions related to } \\
\text { reading, writting, listening, oral/ } \\
\text { Instructions/buttons/etc... }\end{array}$ \\
\hline Listen & Earphones & $\begin{array}{l}\text { Screen access } \\
\text { to a listening } \\
\text { configuration }\end{array}$ & $\begin{array}{l}\text { Headphones } \\
\text { configuration/ } \\
\text { Volume } \\
\text { configuration }\end{array}$ & $\begin{array}{l}\text { Listening access information } \\
\text { about test questions related to } \\
\text { reading, writting, listening, oral/ } \\
\text { Instructions/buttons/etc... }\end{array}$ \\
\hline Speak & Microphone & $\begin{array}{l}\text { Voice } \\
\text { recognition/ } \\
\text { recording } \\
\text { configuration }\end{array}$ & $\begin{array}{l}\text { Microphone } \\
\text { configuration/ } \\
\text { Volume } \\
\text { configuration }\end{array}$ & $\begin{array}{l}\text { Emit simple words and/or a } \\
\text { conversation about test questions } \\
\text { related to reading, writting, } \\
\text { listening, oral/Instructions } \\
\text { confirmation/etc.. }\end{array}$ \\
\hline Touch & Screen/Tablet & $\begin{array}{l}\text { Screen access } \\
\text { to touch } \\
\text { configuration } \\
\text { on the screen }\end{array}$ & $\begin{array}{l}\text { Resolution screen / } \\
\text { brighness/ contrast } \\
\text { configuration }\end{array}$ & $\begin{array}{l}\text { Select buttons or links access to } \\
\text { the information about test } \\
\text { questions related to reading, } \\
\text { writting, listening, oral/ } \\
\text { Instructions/buttons/etc... }\end{array}$ \\
\hline Keyboard & $\begin{array}{c}\text { Physical/virtual } \\
\text { keyboard }\end{array}$ & $\begin{array}{l}\text { Keyboard } \\
\text { configuration }\end{array}$ & $\begin{array}{l}\text { Key position/ } \\
\text { funtional keys, } \\
\text { virtual screen } \\
\text { keyboard } \\
\text { configuration }\end{array}$ & $\begin{array}{l}\text { Select keys and/or composed } \\
\text { keys of words and phrases to } \\
\text { access to information test and } \\
\text { test questions related to reading, } \\
\text { writting, listening, oral/ } \\
\text { Instructions/buttons/etc... }\end{array}$ \\
\hline Mouse & $\begin{array}{l}\text { hysical/integrated } \\
\text { mouse/pencil }\end{array}$ & $\begin{array}{l}\text { Mouse } \\
\text { configuration }\end{array}$ & $\begin{array}{l}\text { Point and click } \\
\text { screen position }\end{array}$ & $\begin{array}{l}\text { Select buttons and/or links to } \\
\text { access the information about the } \\
\text { english reading, writting, } \\
\text { listening, oral assessment/ } \\
\text { Instructions/ etc... }\end{array}$ \\
\hline View & $\begin{array}{l}\text { Physical/integrated } \\
\text { webcam }\end{array}$ & $\begin{array}{l}\text { Webcam } \\
\text { configuration }\end{array}$ & $\begin{array}{l}\text { WebCam } \\
\text { configuration/ } \\
\text { WebCam recorder } \\
\text { configuration }\end{array}$ & $\begin{array}{l}\text { Create a audiovisual record } \\
\text { information about the english } \\
\text { listening, oral assessment / } \\
\text { Instructions/Record/ } \\
\text { Transmission }\end{array}$ \\
\hline
\end{tabular}

Fig. 1. Input/Out data channels oriented to test on-line design for ELF (Magal-Royo, 2018)

In recent years the term multimodal in computer language level of development has been revitalized due to the technological possibilities offered by most devices currently in use such as mobile phones, digital television, computers, etc. The advances of the Consortium for web accessibility called W3C, currently aims to technologies and interactive development processes accessible over the network. The standards generated by $\mathrm{W} 3 \mathrm{C}$ for the mobile web are the basis of this type of interaction since they comply with all accessibility requirements not only at the digital content level but also with navigation guidelines. 
W3C provides the technologies that facilitate interaction through hearing, sight and touch based on languages such as Voice XML, HXHTML and ENMA, the latter acting as a communication mechanism within a multimodal system such as in a language certification online test.

Therefore, in the future the use of multimodality in the development of language testing will improve communication between the user and the device and will open the doors to a more natural handling of digital content created for this purpose.

In the field of technical and functional feasibility of developing multimodal interfaces for language learning from the point of view of some of the basic skills, various experiences have emerged in the University access language tests as in the case of Spain [9], [10], [11].

In conclusion, we can say that the process of control of interactivity by the user will become a key element in the design and formalization of a certification test. Following criteria have to be taken into account in the process of creating applications with the specific purpose of assessing the knowledge of a foreign language:

- Configuration of communication channels and transmission control of information on digital media.

- Multimodal interactive digital environments controlled by the user.

- Technical accessibility criteria based on W3C that allow access to people with visual and / or cognitive disability.

- Creation of a guided navigation according to the needs of the user.

\section{User experience (UX) as a determining factor in the creation of a standardization applied to an on-line test}

UX performance demands the User-Centered Design (UCD) to developed systems that users need. The aim of UCD in technology is to act as an effective interface for delivering pleasant experiences to users when interacting with computers. It is a flexible interactive design methodology, a philosophy and a discipline that understands and analyses how people use computers, objects and systems to propose, accessible, aesthetically pleasing and easy-to-use interfaces [12]. User experience in Human Computer Interaction (HCI) is described by the ISO 9241-210: 2010 normative as person's perceptions and responses resulting from the use and / or anticipated use of a product, system or service [13].

User experience should therefore be the central axis that marks formal and normative aspects of foreign language assessment tests since it would allow a more effective interaction [14]. At present, several studies investigate this problem from three different points of view -from the formal aspect of the content, from the point of functionality and usability of the test and from the point of the use of interfaces that facilitate efficient interactive navigation. It is precisely the development of the test by the user and the conditions of online access to a digital environment that needs a standardization. The goal is to improve and deepen research aimed at the user experience (UX), 
compared to the technology that is being used among other things because the user already has experience and knowledge in the digital medium [15], [16].

User experience (UX) includes a multidimensional concept and focusses more on human needs and the aspects of beauty, fun, pleasure, and personal growth than on the value of the product or instrument used [17], [18]. In fact, in the design of tests for language learning, it is convenient to consider the identified elements when developing and evaluating designs and provide clear instructions on how to perform mobile collaborative activities [19].

Therefore, it implies the need for standardization from the user's point of view who performs a language knowledge test that helps the creators of this type of exam understand the importance of ergonomic, visual and usability factors as opposed to the control of technical aspects derived from the technologies on which the test is implemented on a digital level. The fact that on-line tests are carried out in one device over another should not influence the fundamental objective that it would be to provide evidence of language knowledge with the same degree of difficulty once the test taker becomes familiar with the way of interactivity and navigability [20]. That means that the bias introduced by the way of delivery should be null, and the student should be able to get similar scores no matter the way of delivery (whether paper, traditional computer or mobile device) is used. Therefore, the aspects related to the user experience in the handling of a test for the knowledge of languages focus on the following aspects:

- Feeling of predictability in application management.

- Sensation of control of the application.

- Effectiveness in execution tasks.

- Safety and reliability of control data (personal data and results).

- Access to follow up information

- Functional Aesthetics

- Easily recognizable interface based on technical and graphic characteristics of the device.

\section{$4 \quad$ Research of on-line tests for foreign language (FL) researchers in ubiquitous devices}

Since more than 10 years ago, there have been pilot experiences that have investigated the use of ubiquitous devices in the learning and development of computerassisted assessments for language learning. Most of experiences initially extrapolated conventional analogue schemes and scenarios (paper examinations) into digital environments on desktop computers that were connected via intranet to an educational network and / or were connected online to the Internet. The creation of these digital on-line exams posed several challenges. They not only focused on the creation of the exam or the test itself on the applications available at the time, but also posed a greater challenge depending on the involved technology and user's environment knowledge. 
Thus, the user should become accustomed to the adaptability to digital medium at a functional and procedural level as well as to other aspects such as visual treatment of digital audiovisual content, interaction between examination and user, method of quantitative and qualitative evaluation of the results obtained, etc. [21].

Different proposals have been presented in various research projects such as OPENPAU, PAULEX-Universitas, and SELECTOR (where the impact on the use of the computer and mobile phones in evaluation and learning processes of a foreign language was verified [22]). While other projects have focused on the user's experience and also on the interactive environments oriented towards the development of on-line language assessment tests. These works have made possible to understand adjusting and customizing user's environment during on-line test through the use of multimodal interfaces, adapted digital content and aesthetics based on user-oriented functional ergonomics.

Knowledge acquired so far has allowed us to analyze a possible normalization context based on a series of parameters oriented towards user experience and access to information in a multimodal manner that will have to be analyzed in future in various educational contexts.

\subsection{Standardization in the implementation of a foreign language knowledge test using ubiquitous devices.}

The standardization concept in the creation of online examination tests using ubiquitous devices needs to be considered from four points of view -1 - The theoretical corpus of the evaluation test that is traditionally based on the verification of the knowledge of the in foreign language skills (writing, grammar, conversation, listening, etc. ), 2- The technological corpus that encompasses technologies capable of supporting interactive access structures to each of the evaluable items. That fulfils as main characteristics the ubiquity in the access to information, the interoperability of the data of the digital environment between ubiquitous devices and the technical accessibility to the information shown; 3- The functional corpus that determines the process of development of the tests including the interactive functional design, the execution of the test and the analysis of the results. This section would include the method of analysis, control and verification of student data that will be processed and displayed on an interactive environment, 4- The corpus of user experience focused on the access parameters that affect the interaction in direct, multimodal and collaborative way according to the needs of the user [23].

All these aspects must be treated and analysed in the conceptual and functional development of a language assessment test since in most cases development is considered as a mere migration between technological scenarios on a specific digital device (Figure 2).

Normalization implies the control or verification of the naturalization process by the test taker and should be taken into account when planning an international language test because it improves the systemic aspect of the functionality regardless of the theoretical corpus applied to assess the language. That obviously means, that it has 


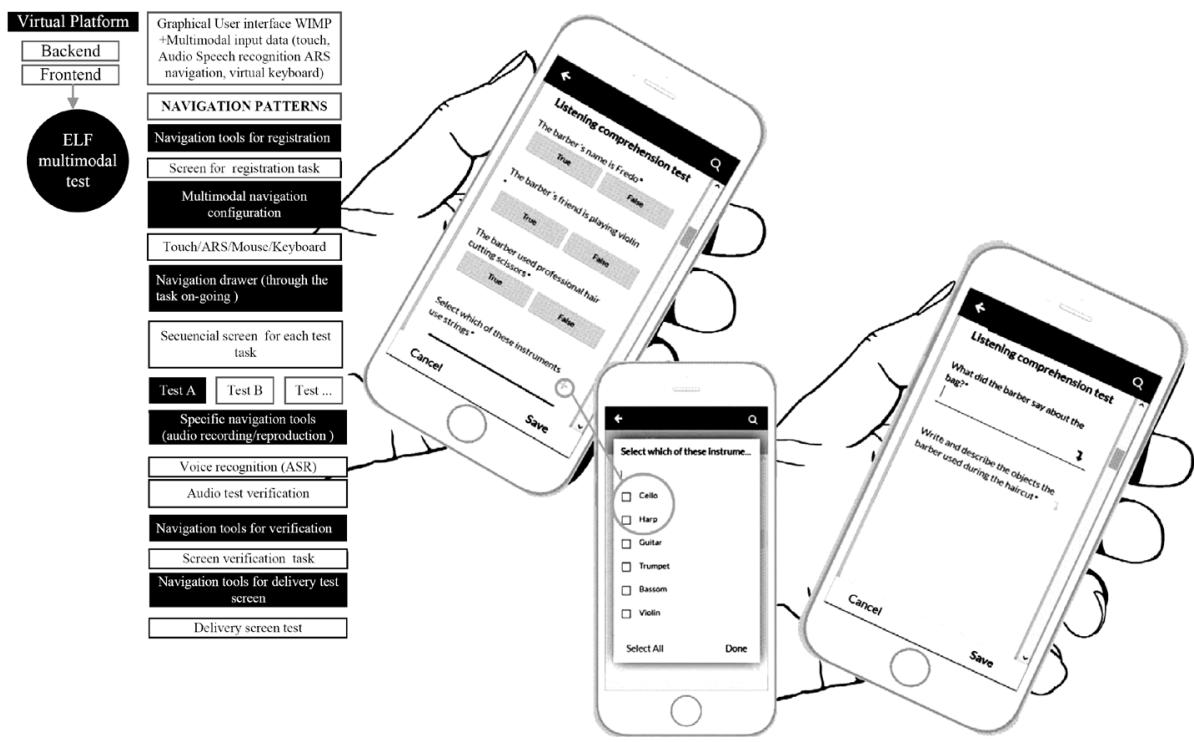

Fig. 2. Scenario of the factors related to the creation of on-line exams for language learning.

(Magal-Royo, 2016)

no or very little effect on the test candidate's performance. Therefore, it is important to note that the aspects to be taken into account in the development of a certifiable language test should work very much in the interactivity aspects with the digital environment from the user experience. by taking into account that the technology and the device is a mere channel of representation that allows us to have the information in the moment. That obviously implies, that normalization and the above null effect of technology on the student's performance is actually the real goal in developing the test to be used on a mobile device. If we propose the systemic regulation based on the use of ubiquitous devices we will also find the paradigm of adaptability and use anywhere that is currently being investigated from the point of view of the active learning methodologies throughout life. Each time the device is less important and it is the type of man-machine communication and the experience that is obtained from it, which should actually orientate the design of both the design of the software and the election of the hardware.

\section{Conclusions}

The need to maximize the user experience during the examination process should be the cornerstone on which the parameters related to standardization in the creation of an online language test should be defined. Until now, the determining factors have been the applied technology and the means by which the on-line examination was implemented and its subsequent evaluation. Nevertheless, currently the user is familiar with the digital medium and the process of conducting tests of languages certification both analogic and digital. 
As a conclusion, we can say that normalization is the only way to reduce of differences among different test takers and avoid undesired bias introduced by the capacity to use mobile devices. That means, when normalization will be achieved tests will measure what they are intended to, that is the learners' knowledge of foreign language. After all, should a test measure anything else other than the student's performance in that foreign language? Of course, not.

\section{References}

[1] Burston, J. (2014). The reality of MALL: still on the fringes. CALICO Journal, Vol. 31 (1) pp. 103-125. https://doi.org/10.11139/cj.31.1.103-125

[2] Kukulska-Hulme, A. \& Viberg, O. (2018). Mobile collaborative language learning: State of the art. British Journal of Educational Technology. Special Issue: Collaborative Learning Enhanced by Mobile Technologies, Vol. 49, (2) pp. 207-218. https://doi.org/10.1111/ bjet.12580.

[3] Magal-Royo T., \& García-Laborda J., (2016). Technical approach for Foreign Language Acquisition (SLA) testing using Multimodal environments. 5th International Conference on Research in Humanities, Sociology and Education (RHSCE'16) Nov. 29-30, 2016 London (UK). https://doi.org/10.15242/ICEHM.ED111606

[4] Gimeno Sanz, A. (2010). Intermediate Online English: An Example of Self-Access Courseware Development. WorldCALL: International Perspectives on Computer Assisted Language Learning. Routledge, New York, pp. 172-187. ISBN: 9781136831614

[5] Magal-Royo,T., Peris-Fajarnes G. , Montañana I. \& Garcia B. (2007). Evaluation methods on usability of m-learning environments. Interactive mobile technologies Vol. 1 (1), pp.2226 Retrievable from: http://online-journals.org/i-jim/article/view/148

[6] Magal-Royo, T., \& García Laborda, J. (2016). Multimodal Interactivity in Foreign Language Testing. Chapter in Multimodal Interaction with W3C Standards. Springer International Publishing pp. 351-365. https://doi.org/10.1007/978-3-319-42816-1 16

[7] Coppock S. \& Mazlack, L. J. (2004). Multi-modal Data Fusion: A Description. Knowledge-Based Intelligent Information and Engineering Systems. Lecture Notes in Computer Science, 2004, Vol. 3214 pp. 1136-1142. https://doi.org/10.1007/978-3-54030133-2 151

[8] Oviatt, S. (2002) Multimodal interfaces. The human-computer interaction handbook. Chapter 8 - Multichannel and Multimodal User Interfaces L. Erlbaum Associates Inc. pp. 497-554. ISBN:0-8058-3838-4

[9] García Laborda, J., Magal Royo, T., \& Barcena Madera, E. (2015).An overview of the needs of technology in language testing in Spain". Procedia - Social and Behavioral Sciences, Vol. 186, pp. 87-90. https://doi.org/10.1016/j.sbspro.2015.04.210

[10] García Laborda, J., Magal Royo, T., da Rocha Siqueira, J. M. \& Fernández Álvarez, M. (2010). Ergonomics factors in English as a foreign language testing: The case of PLEVALEX. Computers \& Education, Vol. 54 (2), pp.384-391. https://doi.org/10.1016/ j.compedu.2009.08.021

[11] García Laborda, J., Magal Royo, T., Litzler, M.F. \& Giménez López, J.L. (2014). Mobile phones for a University Entrance Examination language test in Spain. Educational Technology \& Society, Vol. 17(2), pp17-30. https://doi.org/10.1016/j.sbspro.2015.07.403

[12] Norman, D. A., \& Draper, S. W. (Editors) (1986). User centered system design: New perspectives on human-computer interaction. CRC Press, Taylor \& Francis Group ISBN. 9781482229639. https://doi.org/10.1201/b15703 
[13] International Standardization Organization, ISO, (2009). Ergonomics of human system interaction-Part 210: Human-centered design for interactive systems. International Standardization Organization (ISO). Switzerland.

[14] Smithson, S. \& Hirschheim, R. (1992). Information systems teaching: a debate on the usersystem interface in end-user computing. Information Systems Journal Vol 2 (1) pp. 61-78 https://doi.org/10.1111/j.1365-2575.1992.tb00067.x

[15] Uther, M. \& Banks, A. P. (2016). The influence of affordances on user preferences for multimedia language learning applications. Behaviour \& Information Technology Vol.35 (4), pp. 277-289. https://doi.org/10.1080/0144929X.2016.1151077

[16] Leung, R., Lumsden, J., \& Fritz, J. (2006). Accommodating special needs users in the evaluation of an m-learning application: A case study. Proceedings of the IADIS Mobile Learning Conference, Dublin, Ireland, pp. 177-184. ISBN. 972-8924-15-1

[17] Zaharias \& Mehlenbacher, (2012). Exploring User Experience (UX) in virtual learning environments. International Journal of Human-Computer Studies 70 (7), 475-477. DOI: 10.1016/j.ijhcs.2012.05.001 https://doi.org/10.1016/j.ijhcs.2012.05.001

[18] Kujala, S., Roto, V., Väänänen-Vainio-Mattila, K., Karapanos, E., \& Sinnelä, A. (2011). UX Curve: A method for evaluating long-term user experience. Interacting with Computers, Vol. 23(5), pp. 473-483. https://doi.org/10.1016/j.intcom.2011.06.005

[19] Kukulska-Hulme, A. (2016). Personalization of language learning through mobile technologies. Cambridge University Press, Cambridge, UK.

[20] Smithson, S. \& Hirschheim, R. (1992). Information systems teaching: a debate on the usersystem interface in end-user computing. Information Systems Journal Vol 2 (1) pp. 61-78. https://doi.org/10.1111/j.1365-2575.1992.tb00067.x

[21] García Laborda, J. \& Litzler, M.F. (2015). From monolingual to bilingual through testing: The OPENPAU Project (FFI2011-22442). Savage, J. (Ed) Language Assessment for Multilingualism: Promoting linguistic diversity and intercultural communication. Studies in Language Testing Cambridge: Cambridge University Press, Vol. (44) pp. 452-464. Retreived from: http://www.beck-shop.de/fachbuch/vorwort/9781316505007 Intro 001.pdf

[22] Magal-Royo, T. Garcia Laborda, J.Gimenez Lopez, J. L., de Juan N. (2015). Structural Analysis of a Tablet PC Based Language. Test. Proceedings of 6th World Conference on Educational Sciences. Book Series: Procedia Social and Behavioral Sciences, Vol. 191, pp. 2169-2173. https://doi.org/10.1016/j.sbspro.2015.04.612

[23] Roth, L. \& Bartholome, L., (1994). The relationship between user participation in systemsdevelopment and user satisfaction. Journal of Computer Information Systems, Vol 35 (1), pp. $7-12$

\section{Authors}

Teresa Magal-Royo. PhD in Fine Arts, Associate Professor at the Graphic Engineering Department. Degree: Product Design Universitat Politécnica de Valencia, Spain. Post graduate in the Royal College of Art, London, England. Developing and coordinating projects related to the use of new technology in the field of education/Design and development of user-oriented interfaces/ Adaptation of graphic interfaces for viewing on mobile devices/ usability and accessibility in digital communication devices and in product design for business. /Multimodal interfaces user oriented for ubiquitous devices. She has participated in several national and international research projects on the use of technology in education. (http://www.upv.es/ficha- 
Paper-Standardization of Design Interfaces Applied to Language Test on-line through Ubiquitous Devi...

personal/tmagal, Researcher ID: K-6728-2014, ORCID: http://orcid.org/0000-0002$7640-6264$

Jesús García Laborda Associate Professor and Head of the Department of Modern Philology, Alcalá de Henares, Madrid, Spain. Doctor in English Philology (2000) and European Doctor in Didactics (2010). His research fields are Didactics of language and literature; Languages for specific purposes; Evaluation; English as Foreign Language, ELF, Computer Assisted Language Learning, CALL. (https://portal.uah.es/ portal/page/portal/epd2 profesores/prof153604, Researcher ID: E-1797-2012, ORCID: https://orcid.org/0000-0003-0125-4611)

Article submitted 23 March 2018. Resubmitted 16 June 2018. Final acceptance 09 August 2018. Final version published as submitted by the authors. 